\title{
Identification and Characterization of the CCoAOMT Gene Family in Apple, Chinese White Pear, and Peach
}

\author{
Leli Li \\ College of Horticulture, Nanjing Agricultural University, Nanjing, Jiangsu 210095, China; and \\ Department of Biology, Lund University, 22362 Lund, Sweden
}

Shutian Tao, Huangwei Zhang, and Weijian Huang

College of Horticulture, Nanjing Agricultural University, Nanjing, Jiangsu 210095, China

Jim M. Dunwell

School of Agriculture, Policy and Development, University of Reading, Earley Gate, Reading, UK

Meng Li

College of Horticulture, Nanjing Agricultural University, Nanjing, Jiangsu 210095, China

Additional INDEX words. caffeoyl-CoA 3-O-methyltransferase, lignin

\begin{abstract}
Lignin is one of the main components of plant cell walls, which provides mechanical support for plants and also contributes to resisting against plant pathogenic fungi. In the fruit industry, the lignin content can affect the quality of fruit. The biosynthesis of lignin involves a variety of enzymes, of which caffeoyl-CoA 3-O-methyltransferase $(C C o A O M T)$ is a class of methyltransferases that plays an essential role in lignin biosynthesis. Studies have been conducted on the CCOAOMT gene family in several species, including arabidopsis (Arabidopsis thaliana), black poplar (Populus nigra), and cotton (Gossypium hirsutum). Still, there is relatively little research on this gene family in the Rosaceae. In this study, we used bioinformatics to identify and characterize the CCoAOMT gene family in apple (Malus domestica), chinese white pear (Pyrus bretschneideri), and peach (Prunus persica). In total, 35 CCoAOMT genes were identified in the three Rosaceae species: 8 from chinese white pear, 12 from apple, and 15 from peach. By using structure analysis and collinearity analysis, we found 12 conserved motifs and 12 pairs of $C$ CoAOMT genes with collinearity. In the phylogenetic tree, the gene family was mainly divided into two groups. The genes had different expression patterns during the growth and development stage of fruit, a finding that is consistent with the pattern of lignin accumulation. This study will be beneficial for further study of $C$ CoAOMT genes.
\end{abstract}

Lignin is one of the main components of plant cell walls. It is a phenol polymer composed of coniferyl alcohol, sinapyl alcohol, and p-coumaryl alcohol subunits. Lignin can enhance the strength of cell walls to maintain a plant's structure and also act as a barrier against pathogen infection. When plants are infected by pathogens, the enzymes related to lignin biosynthesis become active, and the lignin content accumulates to resist the pathogen (Huang, 2001). At a global level, lignin is one of the most abundant renewable biomass resources on earth and is widely associated with a range of industrial and agricultural production systems. However, in some contexts, the existence of lignin can cause some problems. For example, the lignin in animal feed has a deleterious effect on the efficiency of digestion and absorption (Srivastava et al., 2012).

In the fruit industry, attention needs to be paid to the effect of lignin on fruit quality. On one hand, as mentioned, lignin

Received for Publication 3 June, 2020. Accepted for Publication 8 Feb. 2021. Published online 29 April 2021.

This project was supported by National Natural Science Foundation of China (Grant No. 31972361).

The study involved no human participants and no animals. The authors declare that they have no competing interests.

L.L. and S.T. contributed equally to this work

M.L. is the corresponding author. E-mail: mli@njau.edu.cn.

This is an open access article distributed under the CC BY-NC-ND license (https://creativecommons.org/licenses/by-nc-nd/4.0/). can resist plant pathogenic fungi and thereby help avoid any decrease in fruit quality. For example, gray mold caused by Botrytis cinerea is a common fungal disease in postharvest apple [Malus domestica (Tang et al., 2012; Yuan et al., 2014)]. When an apple is infected with this pathogen, it will rot and with it comes a decline in fruit quality, even under cold storage conditions. Although there are some agricultural methods to resist this disease, enhancing apple's inherent disease resistance is the most effective method. The induction of lignin synthesis and other phenolic compounds may help in this approach (Valentines et al., 2005).

The content of lignin itself can affect other aspects of fruit quality, and the most representative example is the effect of lignin on the quality of chinese white pear fruit (Pyrus bretschneideri). Stone cells, formed by the accumulation of lignin and other substances, represent one crucial factor that affects the taste of fruit (Rogers and Campbell, 2004). The stone cells mainly exist in groups, and the size and the diameter of these groups both affect the taste of such fruit (Qiao et al., 2005). The russet pericarp characteristic is another specific factor that affects the appearance of pear (Pyrus sp.) fruit. This color of the pericarp is formed by the accumulation of the cork layer (Teng et al., 2005), of which lignin is one of the main components (Lopes et al., 2001; Pereira, 1988). Another defect related to lignin is found in peach (Prunus persica), a Rosaceae fruit tree that originated in China. The formation of the endocarp of peach 
seed is a process dependent on lignification. During the growth and development of peach fruit, a split-pit phenomenon may occur in which the suture of the endocarp does not close tightly or has an obvious gap (Yang et al., 2009); this causes the fruit to be easily infected by a disease. A study has found that the closure mechanism of the peach endocarp is similar to the development of the silique in arabidopsis [Arabidopsis thaliana (Tani et al., 2009)]. It is known that certain transcription factors affect the cracking of the silique by regulating the lignification in this species, and this accumulation of lignin may be related to the split-pit phenomenon of peach fruit (Hu et al., 2012). Therefore, studying the mechanism of the lignification of such fruit may help control their lignification to increase their commercial value.

Considering the process of lignification, the biosynthesis of lignin begins with a series of complex reactions that produce three major monomers: p-hydroxyphenyl $(\mathrm{H})$ lignin, guaiacyl (G) lignin, and syringyl (S) lignin. These three monomers form lignin (Vanholme et al., 2010). This process involves a variety of enzymes, of which caffeoyl-CoA 3-O-methyltransferases (CCoAOMT), a class of S-adenosyl-L-methionine methyltransferases (Boerjan et al., 2003), plays an important role. CCOAOMT enzymes are encoded by specific gene families, members of which have been cloned from many species, including poplar [Populus (Chen et al., 2000)], arabidopsis (Do et al., 2007), cotton [Gossypium hirsutum (Ni et al., 2010)], Neosinocalamus affinis (Wu et al., 2012), and Citrus maxima (Xu et al., 2014), and there have been studies that have found the specific relationship between the CCOAOMT gene family and the lignin. For example, three members of the CCOAOMT gene family have been cloned from rice (Oryza sativa) and are found to be closely related to the lignification process in this species (Zhao et al., 2004). Similarly, a CCOAOMT gene was cloned from pears, and it was found that the gene expression level was similar to the trend of stone cell production in pear fruit (Wang et al., 2015). Studies on tobacco [Nicotiana tabacum (Zhong et al., 1998)], black poplar [Populus nigra (Zhong et al., 2000)], and alfalfa [Medicago sativa (Guo et al., 2001)] found that the deletion of CCOAOMT genes or the inhibition of CCOAOMT gene expression both reduced the lignin content. The expression of CCOAOMT genes was significantly decreased in transgenic maize (Zea mays) expressing an RNA interference construct and led to a $22.4 \%$ decrease in lignin content ( $\mathrm{Li}$ et al., 2013). Similarly, the tobacco transformed with a full-length RNA interference fragment of CCOAOMT had a reduced level of gene expression and consequently a significant decrease in G-lignin content (Chen et al., 2018). Most recently, compared with the wild type, transgenic Betula platyphylla with antisense CCOAOMT genes showed a significantly lower lignin content (Yao et al., 2019).

At present, much research has been conducted on CCOAOMT genes, and the whole genome sequence of some Rosaceae species has been completed, like apple (Velasco et al., 2010), pear (Wu et al., 2013), and peach (Verde et al., 2013). However, due to the limited bioinformatics analysis of the CCOAOMT gene family in Rosaceae species, we still know little about the characterization of CCOAOMT genes. The present study was designed to identify and analyze characteristics of the CCOAOMT gene family in these representative species of the Rosaceae to explain its collinearity and determine its evolution in these species, including apple, chinese white pear, and peach. The study involved structure analysis, phylogenetic analysis, collinearity analysis, and expression analysis, and was to provide a theoretical basis for further research on the specific function of CCOAOMT genes and lignin biosynthesis.

\section{Material and Methods}

IDENTIFICATION OF CCOAOMT GENES IN APPLE, CHINESE WHITE PEAR, AND PEACH. The entire nucleotide sequences, amino acid sequences, and gene annotation files of pear were downloaded from GigaScience database [GigaDB (Wu et al., 2013)]. The complete nucleotide sequences, amino acid sequences, and gene annotation files of apple were downloaded from the Apple Genome and Epigenome [AGE version 1.1 (Daccord et al., 2017)]. The whole nucleotide sequences, amino acid sequences, and gene annotation files of peach were downloaded from the Genome Database for Rosaceae [GDR (Jung et al., 2019)]. Then we constructed an amino acid sequence database of apple, chinese white pear, and peach to perform protein basic local alignment search tool (BLASTP). The query sequence used in the BLASTP was the CCOAOMT amino acid sequence of arabidopsis (NP_564916.2), which was downloaded from the National Center for Biotechnology Information [NCBI, Bethesda, MD (Theologis et al., 2000)]. The resulting sequences with $\mathrm{E}$ value $\leq$ $10^{-10}$ were treated as candidate $C C O A O M T$ sequences. We used NCBI's CD-Search tool (Lu et al., 2020) to check whether the candidate sequence has the characteristic domain of CCOAOMT. If the candidate proteins contained domain of Methyltransf_3 (PFAM: PF01596), it would be considered as the members of CCOAOMT gene families (Pospiech et al., 1996). Basic data about the CCOAOMT proteins were calculated, including protein length, molecular weight, isoelectric point, and transmembrane helices.

Phylogenetic analysis of CCoAOMt genes in apple, CHINESE WHITE PEAR, AND PEACH. In this study, we used the neighbor joining method of MEGA 5.0 (Tamura et al., 2011) to construct the phylogenetic tree, and the website phyML 3.0 [1 Mar. 2020 (Guindon et al., 2010)] was used to construct the maximum likelihood tree as verification. We chose CCOAOMT genes in arabidopsis as outgroup. The CCOAOMT potential protein sequences of arabidopsis were also identified using BLASTP with E value $\leq 10^{-10}$ among the whole genome. The data of arabidopsis whole protein sequence were downloaded from the Arabidopsis Information Resource [TAIR (Philippe et al., 2012)]. Multiple sequence alignment and neighbor joining tree construction of CCOAOMT protein sequences in apple, chinese white pear, peach, and arabidopsis were performed using MEGA 5.0 with a selection of Poisson model and pairwise deletion of vacant/missing data. The phylogenetic tree was constructed with a bootstrap value of 1000 .

MOTIF ANALYSIS OF CCOAOMT GENES IN APPLE, CHINESE WHITE PEAR, AND PEACH. Motif analysis was performed using the Web site multiple em for motif elicitation [MEME (Bailey and Elkan, 1994)]. Based on the MEME motif, a phylogenetic tree was constructed to combine the information of motifs and phylogenetic analysis.

Positive Selection analysis of CCoAOMT genes in APPLe, CHINESE WHITE PEAR, AND PEACH. The positive selection analysis was based on the preceding motif analysis, and the genes were divided into different groups to be analyzed. First, a multiple sequence alignment of CCOAOMT amino acid sequences was performed using CLUSTALW (Larkin et al., 2007). The alignment 
results and the corresponding nucleotide sequences were input into the pal2nal (Suyama et al., 2006) to generate a file in the format of phylogenetic analysis by maximum likelihood [PAML (Xu and Yang, 2013)]. Then a phylogenetic tree was needed as well. The whole positive selection analysis was performed using the $\mathrm{X}$ version of PAML with a model of codons. The likelihood ratio test (LRT) was also required in this analysis, using the $\chi^{2}$ test to calculate whether there was a significant difference. Four of the different models of PAML were used in this study: M0 (Goldman and Yang, 1994; Yang and Nielsen, 1998), M3, M7, and M8 (Yang, 2000a, 2000b). The LRT statistic between M0 and M3 was used to evaluate whether there was a significant difference in the selection pressure between the sites. The LRT statistic between M8 and M7 was used to evaluate whether there was a positive selection between the sites. If the LRT statistic between M8 and M7 had a significant difference and the $\omega$ value of M8 was more than 1, then the Bayesian method was used to evaluate the positively selected sites.

In general, if the results of a group met these three conditions, the group could be considered to have a positive selection: 1) LRT statistic between M8 and M7 had a significant difference; 2 ) the $\omega$ value of M8 was more than 1; and 3) there existed positively selected sites after evaluation by the Bayesian method.

COLLINEARITY ANALYSIS OF CCOAOMT GENES IN APPLE, CHINESE WHITE PEAR, AND PEACH. Multiple Collinearity Scan X [MCScanX (Tang et al., 2008)] was used to conduct the collinearity analysis of each pair of species using a basic local alignment search tool (BLAST) file, which was obtained by blasting the whole genomes and annotated genes.

EXPRESSION ANALYSIS OF CCOAOMT GENES IN APPLE, CHINESE WHITE PEAR, AND PEACH. To examine the expression of CCOAOMT genes among chinese white pear genes, chinese white pear fruit samples at 15,36, 80, 110, 145, and $167 \mathrm{~d}$ after flowering (DAF) were used (Wu et al., 2013), which was calculated in reads per kilobase million (RPKM). To examine the expression of CCoAOMT genes of peach, the fruit samples of peach at 41, 54, 69, 83, 111, and 125 DAF were used [GEO accession GSE71561 (Zaffolon et al., 2017)]. To examine the expression of CCOAOMT genes in apple fruit, the apple fruit samples (hypanthium) at young fruit stage, expanding stage and maturity stage were collected in Zhengzhou Fruit Research Institute (Zhengzhou, China), Chinese Academy of Agricultural Sciences. The apple samples included the wild accession Xifuhaitang and the cultivar Golden Delicious. The flesh tissues of 0.2 to $0.3 \mathrm{~g}$ apple were ground with liquid nitrogen, and RNA extracted by improved CTAB method 61. According to the Illumina TruSeq (San Diego, CA) RNA sample preparation process, the complementary DNA library was constructed. The size and purity of the complementary DNA library were determined by Agilent DNA1000 kit and Agilent 2100 bioassay (Agilent Technologies, Santa Clara, CA). Raw reads of the experiment are submitted to NCBI SRA database (Bethesda, MD), the accession number of the study is SRR9291270 and SRR9291271. Transcripts per million (TPM) was calculated after sequencing by Illumina technique.

\section{Results}

CCOAOMT GENES IN APPLE, CHINESE WHITE PEAR, AND PEACH. In total, 35 CCOAOMT predicted proteins were identified in the three Rosaceae species: eight from chinese white pear, 12 from apple, and 15 from peach by BLASTP (Table 1). The longest of the 35 sequences is $M D 02 G 1073400$, which has 525 amino acids and a molecular weight of 58272.8. The shortest sequence is MD02G1073300, which has only 74 amino acids and a molecular weight of only 8441.1. The length of most CCOAOMT amino acid sequences is between 100 and 300 amino acids and their molecular weights range from 10,000 to 30,000 . The isoelectric points of CCOAOMT sequences distributed between 4 and 10. Twelve CCOAOMT amino acid sequences were found to have a transmembrane segment: Pbr025246.1, MD16G1119300, MD02G1230900, MD05G1209400, Prupe.1G227100.2, Prup.2G107200.1, Prup. 2G107300.1, Prup.4G148100.3, Prup.4G148100.4, Prupe.4G148100.5, Prupe.4G148100.1, and Prupe.7G131200.1. Their transmembrane segments were similar in length, all between 25 and 30 amino acids. Based on the location of several of the predicted $C C O A O M T$ proteins, a number of them were derived from a single gene, representing splice variations, which is shown in Table 1. Therefore, there are a total of 22 CCOAOMT genes in our study considering the splice variations. However, splice variations are a great source for divergence in function-duplicated genes.

Phylogenetic analysis of CCoAOMT genes in APPle, Chinese WHITE PEAR, AND PEACH. Thirteen CCOAOMT protein sequences were identified in arabidopsis. A phylogenetic tree of the CCOAOMT gene family in apple, chinese white pear, peach, and arabidopsis was constructed (Fig. 1). The phylogenetic tree was divided into two groups: A and B. The A group consisted of 39 sequences and the B group consisted of nine sequences. The A group was further divided into four subgroups: A1, A2, A3, and A4. The A1 subgroup included only the CCoAOMT genes from apple, chinese white pear, and peach, indicating that this group was a unique group of Rosaceae. The A2 subgroup included only CCOAOMT genes in arabidopsis. The A3 subgroup did not have the CCOAOMT genes of chinese white pear, and there was only one CCOAOMT gene from arabidopsis (AT4G26220.1) in this subgroup. These results indicated that the differentiation of A1 and A2 was after the species divergence. The A4 subgroup and B group all contained CCOAOMT genes from the four species. The sequence distribution of the A4 subgroup and B group was similar: CCOAOMT genes of apple and chinese white pear were in the closest position of the phylogenetic tree, and CCOAOMT genes of peach and arabidopsis each had a separate branch. Among the 35 CCoAOMT proteins identified in the Rosaceae species, the CCOAOMT genes in apples and chinese white pear were always the most similar. The distribution of CCOAOMT genes on the phylogenetic tree was consistent with their species taxonomy (Fig. 2).

Motif ANALYSIS IN CCOAOMT GENE FAMILY OF APPLE, CHINESE WHITE PEAR, AND PEACH. Twelve conserved motifs were predicted in this study. The conserved motifs, together with a phylogenetic tree, were integrated into the same figure (Fig. 3). This figure was divided into four blocks named 1,2, 3, and 4. None of the 12 motifs existed in all sequences, and motifs $1,2,3,4,5,7$, and 8 frequently appeared in the sequences. Motifs 6 and 11 were only present in the six sequences of block 4: Pbr025246.1, MD05G1209400, Prupe.4G148100.3, Prupe.4G148100.4, Prupe.4G148100.5, and Prup.4G148100.1, which were on the same branch of the phylogenetic tree. Except for Prupe.8G128100.3, seven genes among the eight sequences in block 3 all had motif 12; these seven genes were Prupe.7G131200.1, Prupe.8G128100.1, Prupe.8G128100.4, Pbr038709.1, MD05G1209400, Pbr034039.1, and MD00G1088100. MD02G1073300 had only one motif, because this sequence only had 74 amino acids. MD02G1073400 had the most motifs, of which motifs 1, 2, 3, 4, 5, 7, and 9 all appeared twice. 
Table 1. Basic properties of caffeoyl-CoA 3-O-methyltransferase (CCOAOMT) protein genes in apple, chinese white pear, and peach.

\begin{tabular}{|c|c|c|c|c|c|c|c|c|}
\hline Species & No. & Gene & Start & End & $\begin{array}{l}\text { Protein length } \\
\text { (amino acids) }\end{array}$ & $\begin{array}{l}\text { Molecular wt } \\
\text { (Da) }\end{array}$ & $\mathrm{pI}^{\mathrm{Z}}$ & Transmembrane \\
\hline \multirow[t]{7}{*}{ Pear } & PbCCoAOMT01 & Pbr015171.1 & 6095377 & 6096533 & 161 & 17590.3 & 8.04 & None \\
\hline & PbCCOAOMT02 & Pbr015180.1 & 6147661 & 6151135 & 235 & 26323.8 & 4.81 & None \\
\hline & PbCCoAOMT04 & Pbr025246.1 & 19507699 & 19511795 & 307 & 34112.3 & 8.84 & \# 1:233-261 29aa \\
\hline & PbCCoAOMT05 & Pbr028157.1 & 254343 & 255523 & 149 & 16337.1 & 8.04 & None \\
\hline & PbCCoAOMT06 & Pbr028166.1 & 313064 & 316536 & 235 & 26308.8 & 4.9 & None \\
\hline & PbCCoAOMT08 & Pbr038709.1 & 10033 & 11412 & 247 & 27814.1 & 5.18 & None \\
\hline & MDCCoAOMT01 & MD00G1088100 & 17871472 & 17873066 & 243 & 27330.6 & 5.97 & None \\
\hline \multirow[t]{7}{*}{ Apple } & MDCCoAOMT02.1 & $M D 02 G 1073100$ & 5899257 & 5901470 & 240 & 26717.9 & 5.17 & None \\
\hline & MDCCoAOMT02.2 & $M D 02 G 1073300$ & 5902929 & 5903673 & 74 & 8441.1 & 4.52 & None \\
\hline & MDCCoAOMT02.3 & MD02G1073400 & 5904355 & 5908568 & 525 & 58272.8 & 5.41 & None \\
\hline & MDCCoAOMT06 & $M D 13 G 1117900$ & 8626272 & 8629143 & 237 & 26678.1 & 4.83 & None \\
\hline & MDCCoAOMT07.1 & $M D 16 G 1118200$ & 8401568 & 8407573 & 251 & 28336.7 & 6.4 & None \\
\hline & MDCCoAOMT07.2 & MD16G1119200 & 8519352 & 8521735 & 235 & 26207.7 & 4.64 & None \\
\hline & MDCCoAOMT07.3 & $M D 16 G 1119300$ & 8523351 & 8524410 & 175 & 19463.9 & 4.48 & \# 1:8-36 29aa \\
\hline \multirow[t]{8}{*}{ Peach } & РpССоАОМТ01.1 & Prupe.1G227100.1 & 24032115 & 24034470 & 234 & 26384.9 & 5.17 & None \\
\hline & РрССоАОМТ01.2 & Prupe.1G227100.2 & 24032115 & 24034470 & 166 & 18885.4 & 5.01 & \# 1:0-24 25aa \\
\hline & РpСCоАОМТ01.3 & Prupe.1G227100.3 & 24032115 & 24033691 & 222 & 25148.5 & 4.85 & None \\
\hline & РpCCоАОМТ02.1 & Prupe.2G107200.1 & 16475915 & 16478143 & 237 & 26847.1 & 5.06 & \# 1:46-71 26aа \\
\hline & РpCСоАОМТ02.2 & Prupe.2G107300.1 & 16478452 & 16480777 & 235 & 26751.3 & 5.72 & \# 1:158-185 28aa \\
\hline & РpССоАОМТ03.1 & Prupe.4G148100.3 & 8460021 & 8464276 & 299 & 33087 & 9.18 & \# 1:219-247 29aa \\
\hline & РрССоАОМТ03.1 & Prupe.4G148100.4 & 8460023 & 8464276 & 294 & 32569.5 & 9.18 & \# 1:219-247 29aa \\
\hline & РрССоАОМТ07.3 & Prupe.8G128100.4 & 15185748 & 15187399 & 246 & 27702.8 & 5.65 & None \\
\hline
\end{tabular}

${ }_{\text {Zsoelectric point. }}$

Positive Selection analysis of CCOAOMT Gene FAMILy in APPLE, CHINESE WHITE PEAR, AND PEACH. A positive selection analysis was performed separately according to the groups A1, A2, A3, A4, and B of Fig. 1. As shown in Table 2, the $\omega$ value of each groups was less than 1 , indicating that the purification selection effect occurred in all five groups. The probability values of the LRT statistic between M3 and M0 of A1, A3, and B groups were less than 0.05 , indicating that the three groups had a significant difference in the selection pressure. In contrast, the other A2 and A4 groups did not have a significant difference in the selection pressure. The LRT statistic between M8 and M7 of each group did not have a significant difference, indicating that there was no positive selection in these five groups. The program evaluated no reliable positively selected site. In conclusion, none of the groups met the three conditions at the same time, so the CCOAOMT genes were considered to have not undergone any positive selection.

Collinearity anAlysis of CCOAOMT GENE FAMILY IN APPLE, CHINESE WHITE PEAR, AND PEACH. Through collinearity analysis by MCSanX, 55,158 pairs of collinear genes were identified in apple and chinese white pear, 18,677 pairs in apple and peach, and 15,331 pairs in peach and chinese white pear. There were 12 pairs of CCOAOMT genes with collinearity, eight pairs were in apple and chinese white pear, two pairs were in apple and peach, and two pairs were in chinese white pear and peach (Table 3, Fig. 4). Six CCOAOMT genes in chinese white pear had collinearity with CCoAOMT genes in other species: Pbr015171.1, Pbr019305.1, Pbr025246.1, Pbr015180.1, Pbr028166.1, Pbr028157.1. These six genes were distributed on Chr5, Chr9, Chr16, and scaffold466.0. Chinese white pear genes Pbr015171.1, Pbr019305.1, Pbr025246.1, Pbr028157.1, and Pbr028157.1 had collinearity with a CCoAOMT gene in apple. Pbr015180.1 and Pbr028166.1 both had collinearity with two CCOAOMT genes in apple and one CCOAOMT gene in peach. Five CCOAOMT genes in apple had collinearity with CCOAOMT genes in other species: MD02G1230800, MD05G1209400, MD13G1117900, MD16G1118200, and MD16G 1119200. These five genes were distributed on Chr02, Chr05, Chr13, and Chr16. Only one CCOAOMT gene Prupe.1G227100.2 in peach had collinearity with CCOAOMT genes in other species; 


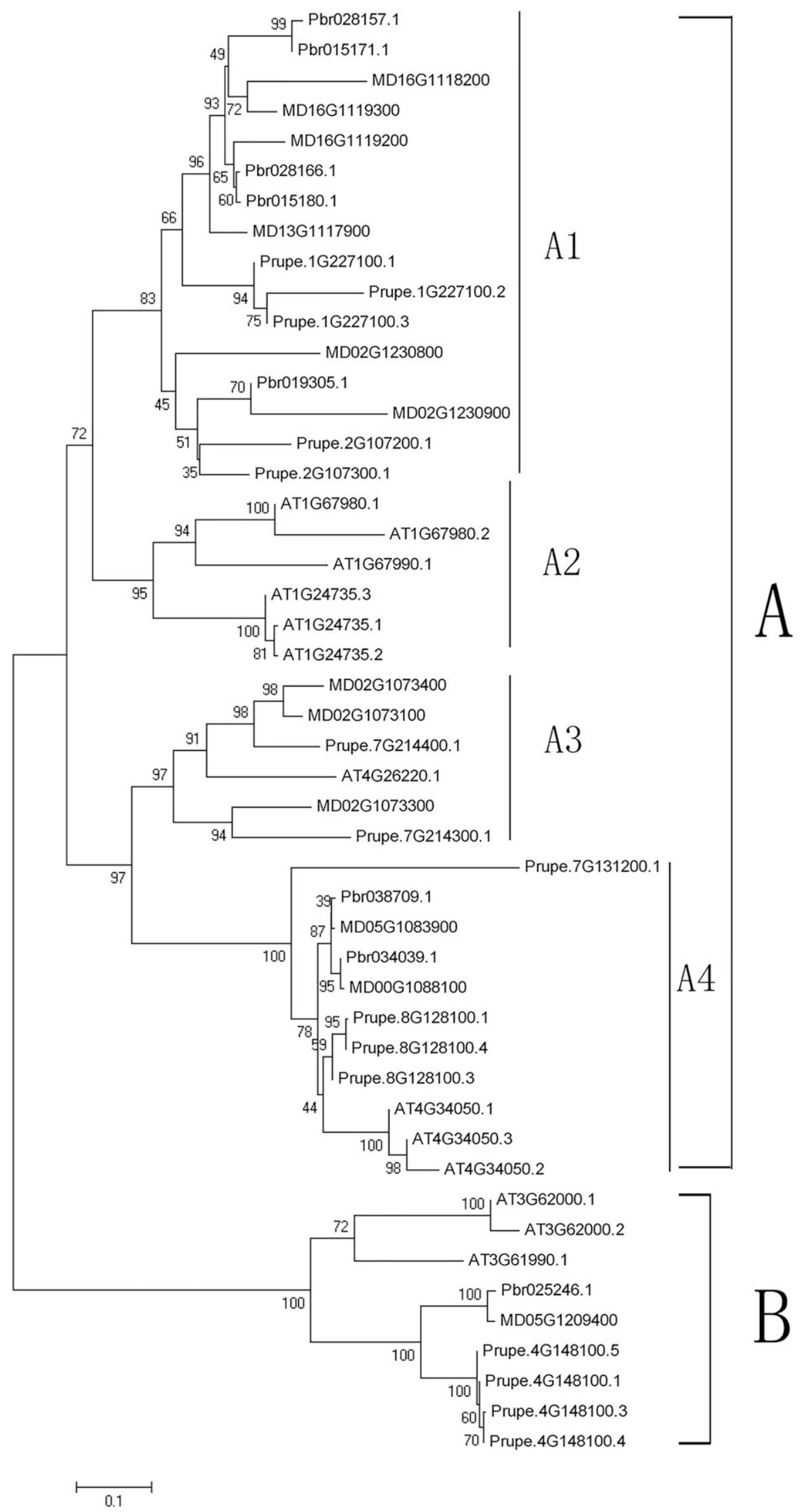

Fig. 1. Phylogenetic tree of caffeoyl-CoA 3-O-methyltransferase (CCOAOMT) gene family in apple, chinese white pear, peach, and arabidopsis. Neighbor joining method of MEGA 5.0 (Tamura et al., 2011) was used to construct the phylogenetic tree with a bootstrap value of 1000. A (A1, A2, A3, A4) and B are different groups of $C$ COAOMT genes. 


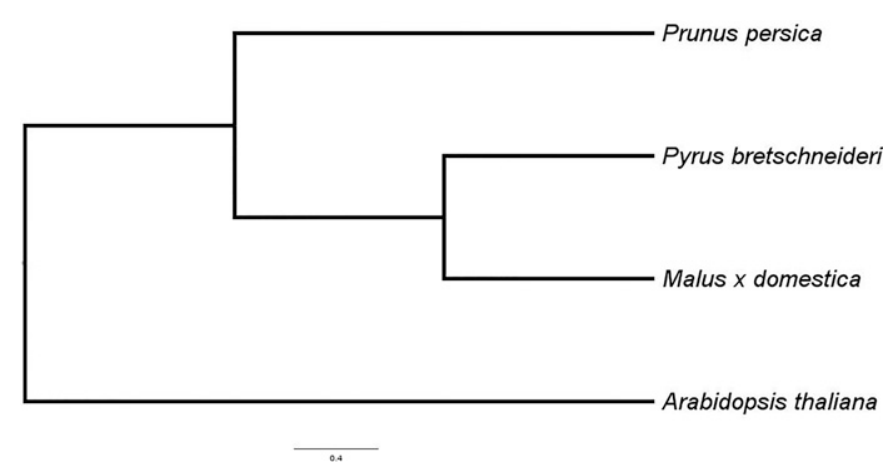

Fig. 2. Species tree of apple, chinese white pear, peach, and arabidopsis.

this gene was located in Chr01. This gene had collinearity with two CCOAOMT genes in apple and two CCOAOMT genes in chinese white pear.

EXPRESSION OF CCOAOMT GENES IN APPLE, CHINESE WHITE PEAR, AND PEACH. To explore the role of CCOAOMT genes in the growth and development of fruit, we examined transcriptome data in chinese white pear, apple, and peach (Figs. 5 and 6). Five genes were expressed differently in different growth and development stages of chinese white pear fruit. Pbr028166.1 was expressed only at 15 DAF (Table 4). Pbr015180.1 was expressed at 15 and $80 \mathrm{DAF}$, and the expression level at $80 \mathrm{DAF}$ was slightly higher than that at $15 \mathrm{~d}$. Pbr019305.1, Pbr025246.1, and Pbr034039.1 expressed in six periods. Both Pbr019305.1 and Pbr034039.1 had a relatively high expression level at $15 \mathrm{DAF}$, and then the expression level of Pbr019305.1 was reduced, whereas the expression level of Pbr034039.1 decreased sharply after the peak at 36 DAF. These two genes were expressed relatively highly at young fruit stage and early expansion stage of chinese white pear fruit $(15,36,80$, and $110 \mathrm{DAF})$, suggesting that the two genes mainly played a role at young fruit stage to expansion stage. The expression level of Pbr025246.1 was stable during these six stages, with a little higher expression level at 110 and 167 DAF.

In apple fruit, four apple CCOAOMT genes were expressed in the transcriptome data (Table 5) with their expression differing at different growth and development stages. MD02G1230800 was only expressed at the young fruit stage of wild apple (Malus sp.) fruit. MD05G1083900 (MD00G1088100) and MD02G1073400 were expressed in all growth and development stages of apple fruit in both wild and cultivated types. The expression level of MD05G1083900 in wild apple was slightly higher than in cultivated apple. Their overall expression levels were lower in cultivated apple and decreased rapidly from young fruit stage to expansion stage. In contrast, their expression levels first increased and then decreased in wild apple. Generally, CCOAOMT genes were expressed at a higher level in wild than in cultivated lines.

The growth and development process of peach fruit can be divided into three stages, and at the second stage, the pericarp is lignified (Chalmers and van den Ende, 1975; Lilien-Kipnis and Lavee, 1971). In peach fruit, the expression levels of Prupe.1G227100.1, Prupe.8G128100.1, Prupe.2G107300.1, and Prupe.7G214400.1 of six stages $(41,54,69,83,111$, and $125 \mathrm{DAF})$ were used (Table 6). It showed the expression levels of all these four genes showed a trend of first rising and then falling, with reaching the highest level in the middle period. This was consistent with the changes of endocarp lignification during the second stage. The expression level of Prupe.1G227100.1 was always low. By contrast, the expression levels of the other three genes were relatively high, which indicated that these three genes played

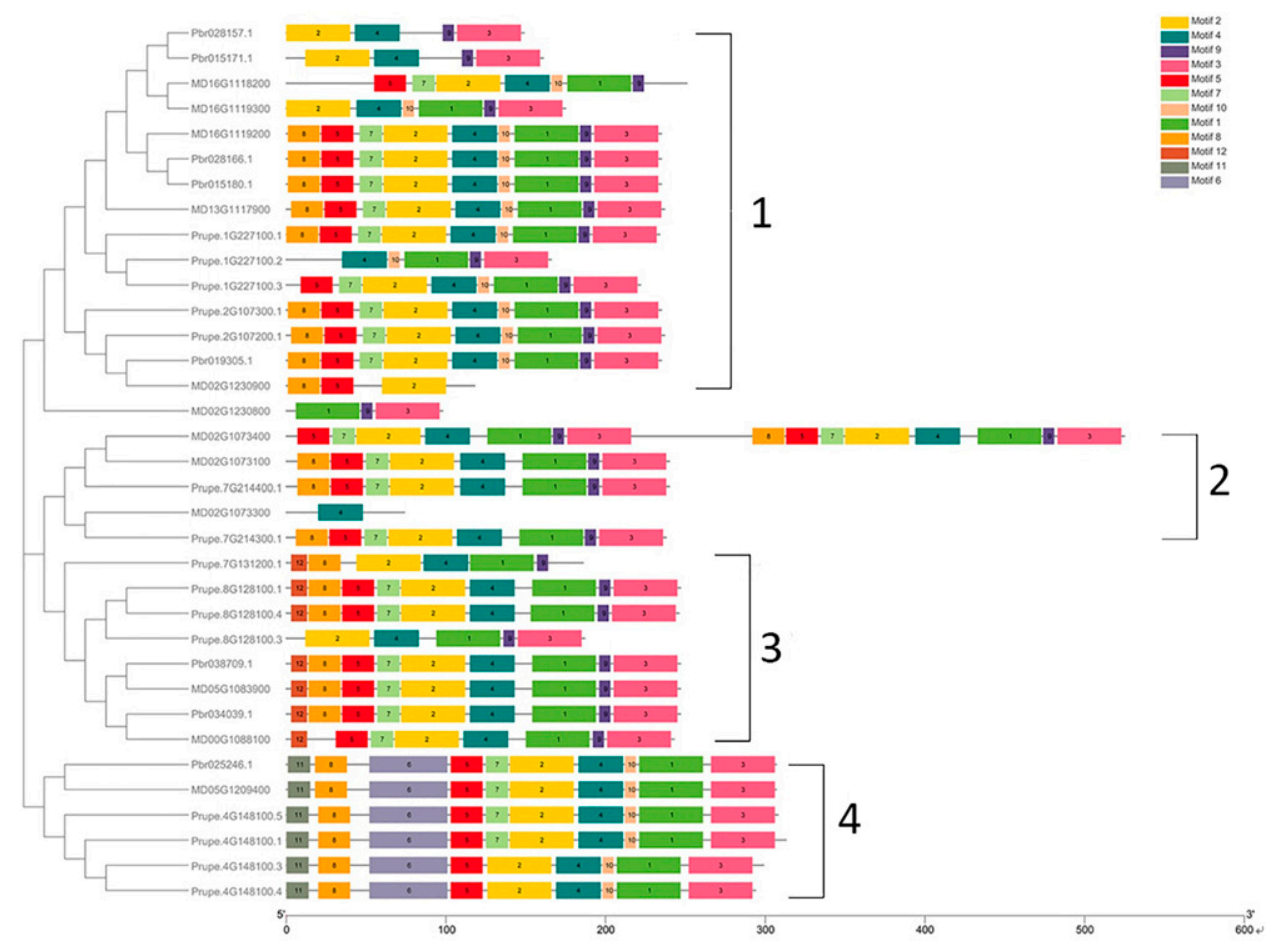

Fig. 3. Motif analysis of caffeoyl-CoA 3-O-methyltransferase (CCOAOMT) gene family in apple, chinese white pear, and peach. Motif analysis was performed using the Web site MEME (Bailey and Elkan, 1994). Motifs are shown in different colors. 
Table 2. Positive selection analysis of caffeoyl-CoA 3-O-methyltransferase (CCoAOMT) genes.

\begin{tabular}{|c|c|c|c|c|c|}
\hline Block & Sequence no. & $\mathrm{dN} / \mathrm{dS}(\omega)$ under $\mathrm{M} 0^{\mathrm{z}}$ & $\begin{array}{c}2 \triangle \mathrm{l}^{\mathrm{y}} \\
\text { M3 vs. M0 }\end{array}$ & $\begin{array}{c}2 \triangle 1 \\
\text { M8 vs. } M 7^{\mathrm{x}}\end{array}$ & M8 estimates ${ }^{\mathrm{w}}$ \\
\hline$\overline{\mathrm{A} 1}$ & 16 & 0.257 & $10.843^{* *}$ & $3.400 * 10-4$ & $P=0.717$ \\
\hline & & & & & $\begin{array}{l}\mathrm{q}=1.117 \\
P 1=0.000 \\
\omega=1.000\end{array}$ \\
\hline A2 & 6 & 0.266 & 18.687 & 0.014 & $\begin{array}{l}P=0.532 \\
\mathrm{q}=1.1783 \\
P 1=0.000 \\
\omega=1.000\end{array}$ \\
\hline A3 & 6 & 0.218 & $37.058 * *$ & 0.391 & $\begin{array}{l}P=0.515 \\
\mathrm{q}=2.783 \\
P l=0.131 \\
\omega=1.092\end{array}$ \\
\hline A4 & 11 & 0.081 & 13.430 & 0.000 & $\begin{array}{l}P=0.655 \\
\mathrm{q}=6.328 \\
P 1=0.000 \\
\omega=1.000\end{array}$ \\
\hline
\end{tabular}

${ }_{\mathrm{z}} \mathrm{dS}=$ synonymous substitution rates, $\mathrm{dN}=$ nonsynonymous substitution rates .

$\mathrm{y}_{2} \triangle 1$ : = twice of the log likelihood difference; M0 (Goldman and Yang, 1994; Yang and Nielsen, 1998); M3, M7, and M8 (Yang, 2000a, 2000b): different models in PAML.

${ }^{x}$ Likelihood ratio test (LRT) value between M3 and M0 and LRT value between M7 and M8. If the $\chi^{2}$ test result is $<0.05$, the data are marked with a "*". If the $\chi^{2}$ test result is $<0.01$, the data are marked with "**".

${ }^{\mathrm{w}} \mathrm{P} 1$ = percentage of positively selected sites; $\mathrm{p}$ and $\mathrm{q}$ are distribution parameters.

The genes were divided into different blocks based on motif analysis.

a major role in period of fruit growth and development. And the expression level of Prupe.8G128100.1 is the highest among these four genes.

\section{Discussion}

Previous studies have found that $C$ COAOMT genes in different species had a certain degree of conservation. These genes in rice, tobacco, grape (Vitis vinifera), maize, and some other species all have unique features characteristic of this gene family.
Also, the CCoAOMT genes have homology in different species. One CCOAOMT gene in cotton has high similarity with CCOAOMT genes in poplar and tobacco (Ni et al., 2010). The CCOAOMT genes in rice are highly similar to those in maize and Bambusa oldhamii (Ni et al., 2010; Zhao et al., 2004). The CCOAOMT genes in sorghum (Sorghum bicolor) have high similarity with those in maize and rice (Rakoczy et al., 2018); but there is a certain degree of difference between these similarities, and these differences may be related to the specific functions of individual CCOAOMT genes.
A

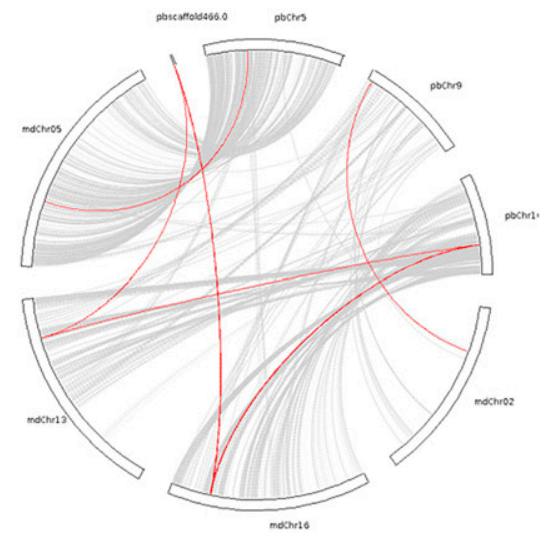

B

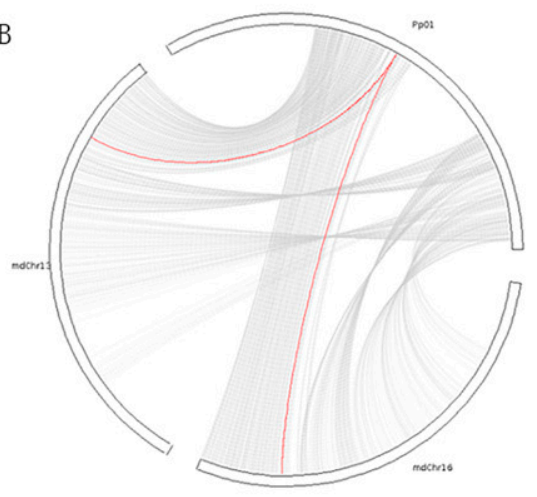

C

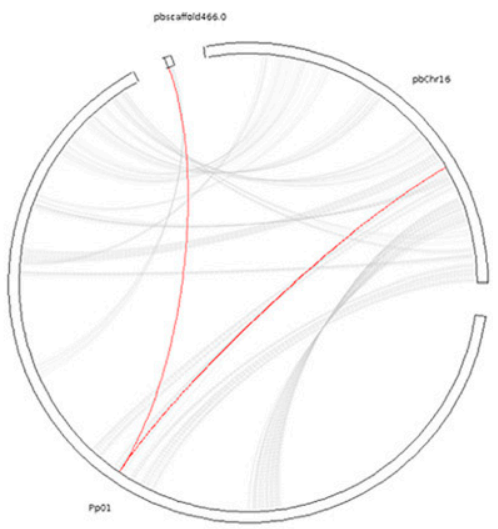

Fig. 4. Collinearity relationship of caffeoyl-CoA 3-O-methyltransferase (CCoAOMT) gene family in apple, chinese white pear, and peach. (A) Collinear genes on Chr5, Chr9, Chr16, and scaffold466.0 of pear with Chr02, Chr05, Chr13, and Chr16 of apple. (B) Collinear genes on Chr13 and Chr16 of apple with Chr01 of peach. (C) Collinear genes on Chr16 and scaffold 466.0 of pear with Chr01 of peach. CCoAOMT genes are indicated in red. 
Table 3. Collinearity relationship of caffeoyl-CoA 3-O-methyltransferase (CCoAOMT) genes in apple, chinese white pear, and peach.

\begin{tabular}{llll}
\hline Gene & Chromosome & Gene & Chromosome \\
\hline Pbr019305.1 & Chr9 & MD02G1230800 & Chr02 \\
Pbr025246.1 & Chr5 & MD05G1209400 & Chr05 \\
Pbr015180.1 & Chr16 & MD13G1117900 & Chr13 \\
Pbr028166.1 & scaffold466.0 & MD13G1117900 & Chr13 \\
Pbr015180.1 & Chr16 & MD16G1118200 & Chr16 \\
Pbr028166.1 & scaffold466.0 & MD16G1118200 & Chr16 \\
Pbr028157.1 & scaffold466.0 & MD16G1119200 & Chr16 \\
Pbr015171.1 & Chr16 & MD16G1119200 & Chr16 \\
Pbr015180.1 & Chr16 & Prupe.1G227100.2 & Chr01 \\
Pbr028166.1 & scaffold466.0 & Prupe.1G227100.2 & Chr01 \\
MD13G1117900 & Chr13 & Prupe.1G227100.2 & Chr01 \\
MD16G1118200 & Chr16 & Prupe.1G227100.2 & Chr01 \\
\hline
\end{tabular}

${ }^{\mathrm{z}}$ Genes in the same row have a collinearity relationship.

In our study, we also found some characteristics of the conservation and homology of CCOAOMT genes in three Rosaceae species. The physical and chemical properties of 35 CCoAOMT proteins were investigated in our study. By predicting the motifs in the sequence, it can be found that there were some similarities in the sequence structure. According to the perverse study of 2013 (Wu et al., 2013), there are nine CCoAOMT genes in chinese white pear and 18 in apple. The difference from our study was caused by the apple genome version, which was the 2017 version we used, and the different criteria.

Studies have shown that Rosaceae originated around the boundary between the early and late cretaceous and whole-genome duplications (WGD) occurred during the evolution of Rosaceae (Xiang et al., 2017). At least a single WGD is shared by both pear and apple (Li et al., 2019), whereas the peach has not undergone recent whole-genome duplication (Verde et al., 2013). From the phylogenetic analysis, we can find that CCOAOMT genes were duplicated. MD02G1073400 had the most motifs, of which the combination of motif 5-motif 7-motif 2-motif 4-motif 1-motif 9-motif 3 was duplicated. It was probably that this sequence had gone through tandem duplication. Motifs 1 (DFIFVDADKDNY), 2 (KLINAKNTMEIGVYTGYSLLATA), 3 (GDGITLCRR), 4 (PVIQKAGVAHKIEF), and 5 (TSVYPREPEPMKELRELT) separately contained a unique tag sequence of

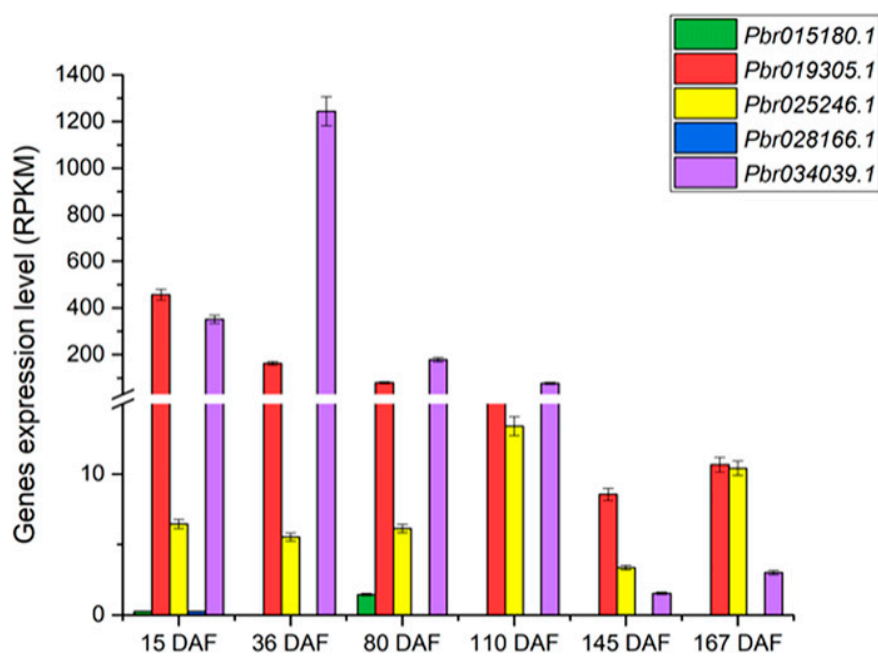

Fig. 5. Expression of caffeoyl-CoA 3-O-methyltransferase (CCOAOMT) genes in chinese white pear fruit at six different stages. $\mathrm{DAF}=$ days after flowering, $\mathrm{RPKM}=$ reads per kilobase million. plant CCoAOMT (Joshi and Chiang, 1998), and most of the 35 sequences contained these five motifs.

The phylogenetic tree of $C C O A O M T$ genes was divided into two main groups, $\mathrm{A}$ and $\mathrm{B}$. Both groups contained CCOAOMT genes in apple, chinese white pear, peach, and arabidopsis, suggesting that the formation of the gene family precedes the differentiation of Rosales and Capparidales. The A group was further divided into A1, A2, A3, and A4 subgroups. The A1 subgroup only contained the genes in apple, chinese white pear, and peach, whereas the A2 subgroup only contained the CCOAOMT genes from arabidopsis. Also we indicated that the duplicated copies (Pbr015180.1-Pbr028166.1) of the chinese white pear genome in A1 are paralogous genes. And Prupe.1G227100.1, Prupe.1G227100.2, and Prupe.1G227100.3 are splice variants of one gene, which are in one branch of the A1 group. We speculated that the differentiation of A1 and A2 occurred after the species divergence and that $\mathrm{A} 1$ and $\mathrm{A} 2$ are orthologous genes. The A3 subgroup lacked the CCOAOMT genes of chinese white pear, probably because genes in chinese white pear did not have these paralogous genes. The A4 subgroup contained two copies of apple CCoAOMT genes, two copies of chinese white pear genes, one copy of peach gene (considering splice variants), and one copy of arabidopsis (considering splice variants), which is as expected with the two duplicated genomes of apple and chinese white pear. The B group contained one copy of apple CCOAOMT gene, one copy of chinese white pear gene, one copy of peach gene (considering splice variants), and two copies of the arabidopsis gene.

Raes et al. (2003) identified seven CCOAOMT genes in arabidopsis. They divided plant CCOAOMT genes into two classes: class I contains one arabidopsis CCOAOMT-1 (AT4G34050) gene with $C C O A O M T$ genes from other plants, whereas class II consists of six arabidopsis CCOAOMT genes and a few sequences from other species. The study indicated that CCOAOMT-5 (AT1G67990) and CCOAOMT-6 (AT1G67980) originated through tandem duplication. In our study, AT1G24735, AT1G67990, and AT1G67980 are located on a separate branch of phylogenetic tree, which are in the A2 group. Also, we found tandem duplications in apple, MD02G1073100-MD02G1073300-MD02G1073400 in A3 group, MD02G1230800-MD02G1230900 in A1 group, MD16G1118200MD16G1119200-MD16G1119300 on another branch of the A1 group. However, there is not enough information on tandem duplication of chinese white pear.

Gene collinearity shows evolutionary conservation of gene sequences on chromosomes. Gene collinearity analysis is the 


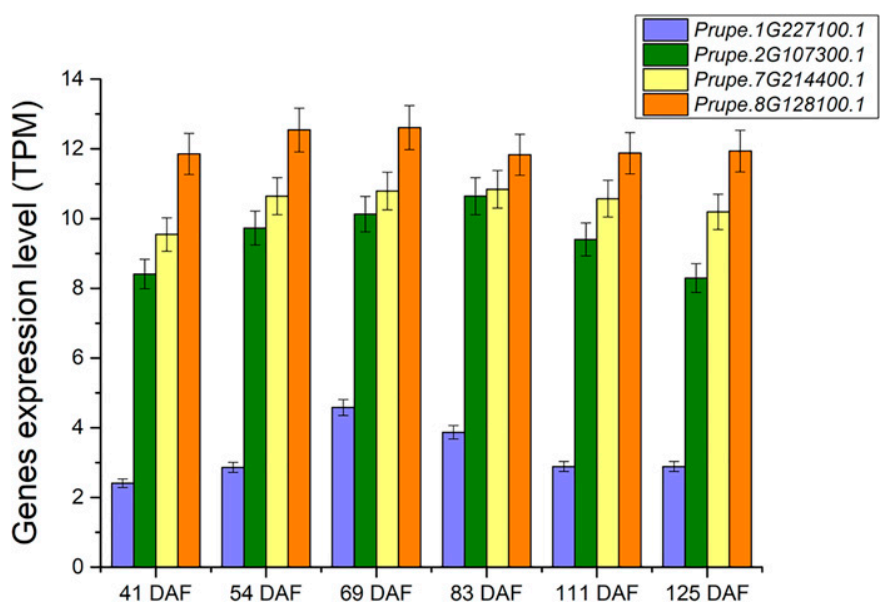

Fig. 6. Expression of caffeoyl-CoA 3-O-methyltransferase (CCOAOMT) genes in peach fruit at six different stages. DAF = days after flowering, TPM = transcripts per million.

basis of comparative genomics, and it can help us to understand the similarities and differences between species and their genetic relationship. It was found that the total of collinear genes between apple and chinese white pear was the most, compared with apple and peach or peach and chinese white pear. This result suggested that pear and apple had a close evolutionary distance.

In this study, PAML was used to perform positive selection analysis. It was found that all four groups had significant differences in selection pressure, but no reliable positive selection sites were found. We could not determine whether the positive selection effect plays a significant role in the evolution of CCOAOMT genes.

The CCOAOMT genes had different expression patterns during fruit growth and development. The apple (MD05G1083900) and chinese white pear (Pbr034039.1) CCoAOMT genes were highly expressed in fruit and decreasing in mature fruit and also the highest expressed in peach (Prupe.8G128100.1) is in the same cluster A4 as CCoAOMT gene in arabidopsis. Stone cells, the formation of which involve the accumulation of lignin and other substances, are important factors affecting the quality. The genes were divided into different blocks based on motif analysis of chinese white pear fruit. Some studies found that after the flowering of pears, the number of stone cells in pear fruit first increased and then decreased during the growth of fruit. In week 7 , the highest peak was reached, and the number of stone cells fell to the lowest when the fruit matured (Liu et al., 2006). Also the study showed that encoding protein of DiCCoAOMT1
Table 4. Expression level of caffeoyl-CoA 3-O-methyltransferase $(C C O A O M T)$ genes in different fruit stages of chinese white pear.

\begin{tabular}{crrrrrc}
\hline & \multicolumn{7}{c}{ Days after flowering } \\
\cline { 2 - 7 } & \multicolumn{1}{c}{15} & 36 & 80 & 110 & 145 & 167 \\
\cline { 2 - 7 } Gene & \multicolumn{7}{c}{ Gene expression (reads per kilobase million) } \\
\hline Pbr015180.1 & 0.26 & $-^{\mathrm{z}}$ & 1.45 & - & - & - \\
Pbr019305.1 & 456.53 & 162.38 & 79.95 & 21.65 & 8.55 & 10.68 \\
Pbr025246.1 & 6.45 & 5.52 & 6.13 & 13.42 & 3.36 & 10.42 \\
Pbr028166.1 & 0.26 & - & - & - & - & - \\
Pbr034039.1 & 351.19 & 1243.92 & 178.45 & 76.86 & 1.54 & 3.00 \\
\hline z- indicates no data. & & & & &
\end{tabular}

demonstrated a relatively high O-methyltransferase activity when using caffeic acid as a substrate in vitro (Wu et al., 2019). We found that the expression trend of Pbr034039.1 was consistent with the findings of the preceding studies, that is, the gene reached a peak at 36 DAF. This finding suggested that Pbr034039.1 was likely to be related to the formation of stone cells.

Cao et al. (2019) identified two true CCoAOMT genes: PbCCoAOMT1 (Pbr034039.1) and PbCCoAOMT2 (Pbr038712.1) in chinese white pear. In their study, PbCCoAOMT2 (Pbr038712.1) showed a 6-fold higher expression level compared with PbCCoAOMT1 (Pbr034039.1) in chinese white pear fruit. Therefore, they inferred that PbCCoAOMT2 (Pbr038712.1) is the most likely candidate involved in lignin biosynthesis of chinese white pear fruit. We found only Pbr034039.1 expressed in our study, which was likely to be related to the formation of stone cells. We can find that the expression of Pbr034039.1 gradually decreases as the fruit develops, which is of the same tendency of Pbr034039.1 in the findings of Cao et al. (2019).

The CCOAOMT genes of apple MD05G1083900 and $M D 00 G 1088100$, which are in the same subgroup of phylogenetic tree with Pbr034039.1 and Pbr038712.1, showed a downward trend during the ripening process of apple cultivars. This may infer the fact that mature cultivar apple fruit do not have a large amount of lignin content. One study has found that the lignin content was lower in the core and flesh of 'Fuji' apple than that in other fruits by comparing the lignin content at the time of optimal harvest in 16 cultivars including japanese pear (Pyrus spp.), chinese white pear, european pear (Pyrus communis) cultivars, quince (Cydonia oblonga), chinese quince (Carica papaya), and apple (Zhang et al., 2020). In contrast, MD05G1083900 (MD00G1088100) showed high expression levels in the late ripening stage of wild apple fruit, which may imply that there is a difference in lignin content between wild apple fruit and cultivated apple fruit. And because

Table 5. Expression level of caffeoyl-CoA 3-O-methyltransferase (CCoAOMT) genes in different fruit stages of apple.

\begin{tabular}{lcccccc}
\hline & \multicolumn{5}{c}{ Fruit stage $^{\mathrm{z}}$} \\
\cline { 2 - 6 } Gene & Cultivated T1 & Wild T1 & Cultivated T2 & Wild T2 & Cultivated T3 & Wild T3 \\
\cline { 2 - 7 } & & \multicolumn{2}{c}{ Gene expression (transcripts per million) } \\
\hline MD02G1073400 & 20.80 & 23.20 & 23.80 & 21.00 & 24.50 & 31.70 \\
MD05G1083900 (MD00G108810) & $-\mathrm{y}$ & 0.75 & - & - & - \\
\end{tabular}

${ }^{\mathrm{z} C u l t i v a t e d}=$ 'Golden Delicious', Wild = Xifuhaitang, T1 = young fruit stages, T2 = enlargement fruit stages, T3 = mature fruit stages.

$\mathrm{y}_{\text {- indicates no data. }}$ 
Table 6. Expression level of caffeoyl-CoA 3-O-methyltransferase $(C C O A O M T)$ genes in different fruit stages of peach.

\begin{tabular}{lcccrrr}
\hline & \multicolumn{6}{c}{ Days after flowering } \\
\cline { 2 - 7 } & 41 & 54 & 69 & 83 & 111 & 125 \\
\cline { 2 - 7 } Gene & \multicolumn{7}{c}{ Gene expression (transcripts } & per million) \\
\hline Prupe.1G227100.1 & 2.41 & 2.86 & 4.58 & 3.87 & 2.89 & 2.89 \\
Prupe.2G107300.1 & 8.41 & 9.73 & 10.13 & 10.65 & 9.40 & 8.30 \\
Prupe.7G214400.1 & 9.55 & 10.64 & 10.79 & 10.84 & 10.57 & 10.20 \\
Prupe.8G128100.1 & 11.86 & 12.54 & 12.61 & 11.83 & 11.88 & 11.94 \\
\hline
\end{tabular}

${ }^{\mathrm{z}}$ The data are the normalization data of raw data [GEO accession GSE71561 (Zaffolon et al., 2017)].

lignin has a certain resistance to stress, it may also indicate that wild apples and cultivated apples have certain disease resistance differences.

For peach fruit, the data we used in the expression analysis are collected from the mesocarp of peach fruit, and we can find that although the expression level of each CCOAOMT genes in peach fruit change during fruit growth and development, the changes are not particularly sharp. Moreover, previous study has found that the expression level of CCOAOMT genes in the endocarp was significantly higher than that in the mesocarp and exocarp, which indicates that the CCOAOMT genes in peaches were largely endocarp specific (Dardick et al., 2010). Therefore, our result may indicate this feature. A similar lignification process was also found in the fruit of wild roses (Rosa multiflora) during the period of fruit growth and development through anatomic study. The fruit of these five species were same as peach fruit, which contained endocarp, mesocarp, and exocarp (Guzicka et al., 2012). In addition, the data are from microarrays, hence not all the genes are necessarily on the array and, depending on the oligos used, they may not discriminate between the splice variants. Rosaceae species also have different fruit types, such as fruits of some achenetum, of which the fruit are dried. In general, the relationship between the structure and the lignification changes of Rosaceae fruit deserves more related studies.

Apple and chinese white pear are duplicated genomes and peach is not; however, the CCOAOMT gene numbers are similar in these three fruits. This would indicate that the CCoAOMT gene was not in the tandem duplication area of the genome. Also, from our study we can tell that although the results can give us useful information of CCOAOMT genes, there can be misannotation of some of the genes. More accurate genome information is needed to conduct a following study.

\section{Literature Cited}

Bailey, T.L. and C. Elkan. 1994. Fitting a mixture model by expectation maximization to discover motifs in biopolymers. Proc. Intl. Conf. Intell. Syst. Mol. Biol. 2:28-36.

Boerjan, W., J. Ralph, and M. Baucher. 2003. Lignin biosynthesis. Annu. Rev. Plant Biol. 54:519-546, doi: 10.1146/annurev. arplant.54.031902.134938.

Cao, Y.P., X.X. Li, and L. Jiang. 2019. Integrative analysis of the core fruit lignification toolbox in pear reveals targets for fruit quality bioengineering. Biomolecules 9:504, doi: 10.3390/biom9090504.

Chalmers, D.J. and B. van den Ende. 1975. A reappraisal of the growth and development of peach fruit. Austral. J. Plant Physiol. 2: 623-634, doi: 10.1071/pp9750623.
Chen, B.W., H.L. Liu, Y.F. Xiao, Z.H. Qin, Y. Zhang, and X.N. Zhang. 2018. Directional regulation of lignin monomer synthesis in tobacco by using COMT gene and CCOAOMT gene of Eucalyptus urophylla. China Biotechnol. 38:24-32. (in Chinese), doi: 10.13523/ j.cb.20180304.

Chen, C., H. Meyermans, B. Burggraeve, R.M. De Rycke, K. Inoue, V. De Vleesschauwer, M. Steenackers, M.C. Van Montagu, G.J. Engler, and W.A. Boerjan. 2000. Cell-specific and conditional expression of caffeoyl-coenzyme A-3-O-methyltransferase in poplar. Plant Physiol. 123:853-867, doi: 10.1104/pp.123.3.853.

Daccord, N., J.M. Celton, G. Linsmith, C. Becker, N. Choisne, E. Schijlen, H. van de Geest, L. Bianco, D. Micheletti, R. Velasco, E.A. Di Pierro, J. Gouzy, D.J.G. Rees, P. Guérif, H. Muranty, C.E. Durel, F. Laurens, Y. Lespinasse, S. Gaillard, S. Aubourg, H. Quesneville, D. Weigel, E. van de Weg, M. Troggio, and E. Bucher. 2017. High-quality de novo assembly of the apple genome and methylome dynamics of early fruit development. Nat. Genet. 49:10991106, doi: 10.1038/ng.3886.

Dardick, C.D., A.M. Callahan, R. Chiozzotto, R.J. Schaffer, M.C. Piagnani, and R. Scorza. 2010. Stone formation in peach fruit exhibits spatial coordination of the lignin and flavonoid pathways and similarity to Arabidopsis dehiscence. BMC Biol, doi: 10.1186/ 1741-7007-8-13.

Do, C.T., B. Pollet, J. Thévenin, R. Sibout, D. Denoue, Y. Barrière, C. Lapierre, and L. Jouanin. 2007. Both caffeoyl coenzyme A 3-Omethyltransferase 1 and caffeic acid O-methyltransferase 1 are involved in redundant functions for lignin, flavonoids and sinapoyl malate biosynthesis in Arabidopsis. Planta 226:1117-1129, doi: 10.1007/s00425-007-0558-3.

Goldman, N. and Z.H. Yang. 1994. A codon-based model of nucleotide substitution for protein-coding DNA sequences. Mol. Biol. Evol. 11:725-736, doi: 10.1093/oxfordjournals.molbev.a040153.

Guindon, S., J.F. Dufayard, V. Lefort, M. Anisimova, W. Hordijk, and O. Gascuel. 2010. New algorithms and methods to estimate maximum-likelihood phylogenies: Assessing the performance of PhyML 3.0. Syst. Biol. 59:307-321, doi: 10.1093/sysbio/syq010.

Guo, D., F. Chen, K. Inoue, J.W. Blount, and R.A. Dixon. 2001. Downregulation of caffeic Acid 3-O-methyltransferase and caffeoyl CoA 3-O-methyltransferase in transgenic alfalfa: Impacts on lignin structure and implications for the biosynthesis of $\mathrm{G}$ and $\mathrm{S}$ lignin. Plant Cell 13:73-88, doi: 10.2307/3871154.

Guzicka, M., J. Zieliński, D. Tomaszewski, and M. Gawlak. 2012. Anatomical study on the developing pericarp of selected Rosa species (Rosaceae). Dendrobiology 66:77-87, doi: 10.4067/S0717-92002012000200014.

Hu, H., Y. Liu, Y.P. Liu, R.J. Wu, B.G. Hua, and Y.N. Wang. 2012. Cloning and expression analysis of PpNST1 and PpSND1 genes from Prunus persica L. Plant Physiol. J. 48:589-596. (in Chinese), doi: 10.13592/j.cnki.ppj.2012.06.003.

Huang, J.S. 2001. Plant pathogenesis and resistance. Springer, Dordrecht, The Netherlands.

Joshi, C.P. and V.L. Chiang. 1998. Conserved sequence motifs in plant S-adenosyl-L-methionine-dependent methyltransferases. Plant Mol. Biol. 37:663-674, doi: 10.1023/A:1006035210889.

Jung, S., T. Lee, C. Cheng, K. Buble, P. Zheng, J. Yu, J. Humann, S.P. Ficklin, K. Gasic, K. Scott, M. Frank, S. Ru, H. Hough, K. Evans, C. Peace, M. Olmstead, L.W. DeVetter, J. McFerson, M. Coe, J.L. Wegrzyn, M.E. Staton, A.G. Abbott, and D. Main. 2019. 15 years of GDR: New data and functionality in the Genome Database for Rosaceae. Nucleic Acids Res. 47:D1137-D1145, doi: 10.1093/ nar/gky1000.

Larkin, M.A., G. Blackshields, N.P. Brown, R. Chenna, P.A. McGettigan, H. McWilliam, F. Valentin, I.M. Wallace, A. Wilm, R. Lopez, J.D. Thompson, T.J. Gibson, and D.G. Higgins. 2007. Clustal W and Clustal X version 2.0. Bioinformatics 23:2947-2948, doi: 10.1093/ bioinformatics/btm 404 . 
Li, H., C.-H. Huang, and H. Ma. 2019. Whole-genome duplications in pear and apple, p. 279-299. In: S. Korban (ed.). The pear genome. Springer, Dordrecht, The Netherlands.

Li, X., W. Chen, Y. Zhao, Y. Xiang, H. Jiang, S. Zhu, and B. Cheng. 2013. Downregulation of caffeoyl-CoA O-methyltransferase $(C C O A O M T)$ by RNA interference leads to reduced lignin production in maize straw. Genet. Mol. Biol. 36:540-546, doi: 10.1590/S1415-47572013005000039.

Lilien-Kipnis, H. and S. Lavee. 1971. Anatomical changes during the development of 'Ventura' peach fruits. J. Hort. Sci. 46:103-110, doi: 10.1080/00221589.1971.11514388.

Liu, X.Y., G.Z. Gao, H.X. Li, and Z.Q. Lei. 2006. Dynamic study on fruit development and the formation of stone cells in 'Dangshansuli'. J. Huaibei Coal Ind. Teach. Coll. 27:49-53. (in Chinese), doi: 10.3969/j.issn.2095-0691.2006.01.012.

Lopes, M.H., A.S. Barros, N.C. Pascoal, D. Rutledge, I. Delgadillo, and A.M. Gil. 2001. Quantitation of aliphatic suberin in Quercus suber L. cork by FTIR spectroscopy and solid-state 13C-NMR spectroscopy. Biopolymers 62:268-277, doi: 10.1002/1097-0282(2000) 57:6<344:AID-BIP40>3.0.CO;2-\#.

Lu, S., J. Wang, F. Chitsaz, M.K. Derbyshire, R.C. Geer, N.R. Gonzales, M. Gwadz, D.I. Hurwitz, G.H. Marchler, J.S. Song, N. Thanki, R.A. Yamashita, M. Yang, D. Zhang, C. Zheng, C.J. Lanczycki, and A. Marchler-Bauer. 2020. CDD/SPARCLE: The conserved domain database in 2020. Nucleic Acids Res. 48:D265-D268, doi: 10.1093/nar/gkz991.

Ni, Z.Y., M. Lu, and L. Fan. 2010. Cloning and Characterization of CCoAOMT Gene from Gossypium hirsutum L. Acta Bot. Bor-Occid Sin. 30:1083-1091. (in Chinese), doi: 10.3724/SP.J.1142.2010.40466.

Raes, J., A. Rohde, J.H. Christensen, Y. Van de Peer, and W. Boerjan. 2003. Genome-wide characterization of the lignification toolbox in Arabidopsis. Plant Physiol. 133:1051-1071, doi: 10.1104/pp.103.026484.

Pereira, H. 1988. Chemical composition and variability of cork from Quercus suber L. Wood Sci. Technol. 22:211-218, doi: 10.1007/ BF00386015.

Philippe, L., T.Z. Berardini, D. Li, D. Swarbreck, C. Wilks, R. Sasidharan, R. Muller, K. Dreher, D.L. Alexander, M. GarciaHernandez, A.S. Karthikeyan, C.H. Lee, W.D. Nelson, L. Ploetz, S. Singh, A. Wensel, and E. Huala. 2012. The Arabidopsis information resource (TAIR): Improved gene annotation and new tools. Nucleic Acids Res. 40:D1202-D1210, doi: 10.1093/ nar/gkr1090.

Pospiech, A., J. Bietenhader, and T. Schupp. 1996. Two multifunctional peptide synthetases and an O-methyltransferase are involved in the biosynthesis of the DNA-binding antibiotic and antitumour agent saframycin Mx1 from Myxococcus xanthus. Microbiology 142:741-746, doi: 10.1006/mpat.1996.0023.

Qiao, Y.J., S.L. Zhang, S.T. Tao, Z.M. Zhang, and Z.L. Liu. 2005. Advances in research on developing mechanism of stone cells in pear fruit. J. Fruit Sci. 22:367-371. (in Chinese), doi: 10.3969/j. issn.1009-9980.2005.04.015.

Rakoczy, M., I. Femiak, M. Alejska, M. Figlerowicz, and J. Podkowinski. 2018. Sorghum CCoAOMT and CCoAOMT-like gene evolution, structure, expression and the role of conserved amino acids in protein activity. Mol. Genet. Genomics 293:113, doi: 10.1007/s00438-018-1441-6.

Rogers, L.A. and M.M. Campbell. 2004. The genetic control of lignin deposition during plant growth and development. New Phytol. 164: 17-30, doi: 10.1111/j.1469-8137.2004.01143.x.

Srivastava, S., V. Mudgal, and R.K. Jain. 2012. Lignin-its role and importance in animal nutrition. Intl. J. Livest. Res. 2:7-23.

Suyama, M., D. Torrents, and P. Bork. 2006. PAL2NAL: Robust conversion of protein sequence alignments into the corresponding codon alignments. Nucleic Acids Res. 34:W609-W612, doi: 10.1093/nar/ gkl315.

Tamura, K., D. Peterson, N. Peterson, G. Stecher, M. Nei, and S. Kumar. 2011. MEGA5: Molecular evolutionary genetics analysis using maximum likelihood, evolutionary distance, and maximum parsimony methods. Mol. Biol. Evol. 28:2731-2739, doi: 10.1093/ molbev/msrl21.

Tang, H., J.E. Bowers, X. Wang, R. Ming, M. Alam, and A.H. Paterson. 2008. Synteny and collinearity in plant genomes. Science 320: 486-488, doi: 10.1126/science.1153917.

Tang, W., Z. Ding, Z.Q. Zhou, Y.Z. Wang, and L.Y. Guo. 2012. Phylogenetic and pathogenic analyses show that the causal agent of apple ring rot in China is Botryosphaeria dothidea. Plant Dis. 96:486-496, doi: 10.1094/PDIS-08-11-0635.

Tani, E., A.N. Polidoros, E. Flemetakis, C. Stedel, C. Kalloniati, K. Demetriou, P. Katinakis, and A.S. Tsaftaris. 2009. Characterization and expression analysis of AGAMOUS-like, SEEDSTICK-like, and SEPALLATA-like MADS-box genes in peach (Prunus persica) fruit. Plant Physiol. Biochem. 47:690-700, doi: 10.1016/j.plaphy.2009.03.013.

Teng, Y.W., Y.Y. Shen, and X.Z. Zhou. 2005. Cause of rust spots of sand pear and its solution. South China Fruits 34:52-56. (in Chinese), doi: 10.3969/j.issn.1007-1431.2005.03.027.

Theologis, A., J.R. Ecker, C.J. Palm, N.A. Federspiel, S. Kaul, O. White, J. Alonso, H. Altafi, R. Araujo, C.L. Bowman, S.Y. Brooks, E. Buehler, A. Chan, Q. Chao, H. Chen, R.F. Cheuk, C.W. Chin, M.K. Chung, L. Conn, A.B. Conway, A.R. Conway, T.H. Creasy, K. Dewar, P. Dunn, P. Etgu, T.V. Feldblyum, J. Feng, B. Fong, C.Y. Fujii, J.E. Gill, A.D. Goldsmith, B. Haas, N.F. Hansen, B. Hughes, L. Huizar, J.L. Hunter, J. Jenkins, C. Johnson-Hopson, S. Khan, E. Khaykin, C.J. Kim, H.L. Koo, I. Kremenetskaia, D.B. Kurtz, A. Kwan, B. Lam, S. Langin-Hooper, A. Lee, J.M. Lee, C.A. Lenz, J.H. Li, Y. Li, X. Lin, S.X. Liu, Z.A. Liu, J.S. Luros, R. Maiti, A. Marziali, J. Militscher, M. Miranda, M. Nguyen, W.C. Nierman, B.I. Osborne, G. Pai, J. Peterson, P.K. Pham, M. Rizzo, T. Rooney, D. Rowley, H. Sakano, S.L. Salzberg, J.R. Schwartz, P. Shinn, A.M. Southwick, H. Sun, L.J. Tallon, G. Tambunga, M.J. Toriumi, C.D. Town, T. Utterback, S. Van Aken, M. Vaysberg, V.S. Vysotskaia, M. Walker, D. Wu, G. Yu, C.M. Fraser, J.C. Venter, and R.W. Davis. 2000. Sequence and analysis of chromosome 1 of the plant Arabidopsis thaliana. Nature 408:816-820, doi: $10.1038 / 45471$.

Valentines, M.C., R. Vilaplana, R. Torres, J. Usall, and C. Larrigaudière. 2005. Specific roles of enzymatic browning and lignification in apple disease resistance. Postharvest Biol. Technol. 36:227-234, doi: 10.1016/j.postharvbio.2005.01.002.

Vanholme, R., B. Demedts, K. Morreel, J. Ralph, and W. Boerjan. 2010. Lignin biosynthesis and structure. Plant Physiol. 153:895-905, doi: $10.1104 /$ pp.110.155119.

Velasco, R., A. Zharkikh, J. Affourtit, A. Dhingra, A. Cestaro, A. Kalyanaraman, P. Fontana, S.K. Bhatnagar, M. Troggio, D. Pruss, S. Salvi, M. Pindo, P. Baldi, S. Castelletti, M. Cavaiuolo, G. Coppola, F. Costa, V. Cova, A. Dal Ri, V. Goremykin, M. Komjanc, S. Longhi, P. Magnago, G. Malacarne, M. Malnoy, D. Micheletti, M. Moretto, M. Perazzolli, A. Si-Ammour, S. Vezzulli, E. Zini, G. Eldredge, L.M. Fitzgerald, N. Gutin, J. Lanchbury, T. Macalma, J.T. Mitchell, J. Reid, B. Wardell, C. Kodira, Z. Chen, B. Desany, F. Niazi, M. Palmer, T. Koepke, D. Jiwan, S. Schaeffer, V. Krishnan, C. Wu, V.T. Chu, S.T. King, J. Vick, Q. Tao, A. Mraz, A. Stormo, K. Stormo, R. Bogden, D. Ederle, A. Stella, A. Vecchietti, M.M. Kater, S. Masiero, P. Lasserre, Y. Lespinasse, A.C. Allan, V. Bus, D. Chagné, R.N. Crowhurst, A.P. Gleave, E. Lavezzo, J.A. Fawcett, S. Proost, P. Rouzé, L. Sterck, S. Toppo, B. Lazzari, R.P. Hellens, C.E. Durel, A. Gutin, R.E. Bumgarner, S.E. Gardiner, M. Skolnick, M. Egholm, Y. Van de Peer, F. Salamini, and R. Viola. 2010. The genome of the domesticated apple (Malus $\times$ domestica Borkh.). Nat. Genet. 42:833-839, doi: 10.1038/ng.654.

Verde, I., A.G. Abbott, S. Scalabrin, S. Jung, S. Shu, F. Marroni, T. Zhebentyayeva, M.T. Dettori, J. Grimwood, F. Cattonaro, A. Zuccolo, L. Rossini, J. Jenkins, E. Vendramin, L.A. Meisel, V. Decroocq, B. Sosinski, S. Prochnik, T. Mitros, A. Policriti, G. Cipriani, L. Dondini, S. Ficklin, D.M. Goodstein, P. Xuan, C.D. Fabbro, V. 
Aramini, D. Copetti, S. Gonzalez, D.S. Horner, R. Falchi, S. Lucas, E. Mica, J. Maldonado, B. Lazzari, D. Bielenberg, R. Pirona, M. Miculan, A. Barakat, R. Testolin, A. Stella, S. Tartarini, P. Tonutti, P. Arús, A. Orellana, C. Wells, D. Main, G. Vizzotto, H. Silva, F. Salamini, J. Schmutz, M. Morgante, and D.S. Rokhsar. 2013. The highquality draft genome of peach (Prunus persica) identifies unique patterns of genetic diversity, domestication and genome evolution. Nat. Genet. 45:487-494, doi: 10.1038/ng.2586.

Wang, D.Y., F.Y. Gao, W. Sun, W.K. Rui, S. Khanizadeh, S.L. Zhang, and S.T. Tao. 2015. Cloning and expression analysis of CCoAOMT gene in fruit of 'Dangshansuli'. J. Nanjing Agr. Univ. 38:33-40. (in Chinese), doi: 10.7685/j.issn.1000-2030.2015.01.006.

Wu, J., Z. Wang, Z. Shi, S. Zhang, R. Ming, S. Zhu, M.A. Khan, S. Tao, S.S. Korban, H. Wang, N.J. Chen, T. Nishio, X. Xu, L. Cong, K. Qi, X. Huang, Y. Wang, X. Zhao, J. Wu, C. Deng, C. Gou, W. Zhou, H. Yin, G. Qin, Y. Sha, Y. Tao, H. Chen, Y. Yang, Y. Song, D. Zhan, J. Wang, L. Li, M. Dai, C. Gu, Y. Wang, D. Shi, X. Wang, H. Zhang, L. Zeng, D. Zheng, C. Wang, M. Chen, G. Wang, L. Xie, V. Sovero, S. Sha, W. Huang, S. Zhang, M. Zhang, J. Sun, L. Xu, Y. Li, X. Liu, Q. Li, J. Shen, J. Wang, R.E. Paull, J.L. Bennetzen, J. Wang, and S. Zhang. 2013. The genome of pear (Pyrus bretschneideri Rehd.). Genome Res. 23:396-408, doi: 10.1101/gr.144311.112.

Wu, X., Z. Yan, X. Dong, F. Cao, and M. Li. 2019. Cloning and characterization of a CCOAOMT gene involved in rapid lignification of endocarp in dove tree (Davidia involucrata baill.). Biotechnol. Biotechnol. Equip. 32(6):1398-1406, doi: 10.1080/13102818.2018.1525324.

Wu, X.Y., S.L. Hu, Y. Cao, X.Q. Lu, P. Ren, M.J. Zhou, and X.R. Li. 2012. Cloning of CCOAOMT gene in Neosinocalamus affinis and its bioinformatics analysis. J. Nanjing For. Univ. 36:17-22. (in Chinese), doi: 10.3969/j.issn.1000-2006.2012.03.005.

Xiang, Y.Z., C. Huang, Y. Hu, J. Wen, S.S. Li, T.S. Yi, H.Y. Chen, J. Xiang, and H. Ma. 2017. Evolution of Rosaceae fruit types based on nuclear phylogeny in the context of geological times and genome duplication. Mol. Biol. Evol. 34:262-281.

$\mathrm{Xu}, \mathrm{B}$. and Z. Yang. 2013. PAMLX: A graphical user interface for PAML. Mol. Biol. Evol. 30:2723-2724, doi: 10.1093/molbev/mst179.

$\mathrm{Xu}$, Y., T.F. Pan, and D.M. Pan. 2014. Cloning of caffeoyl-coenzyme A O-methyltransferase gene from Citrus maxima (Burm.) Merr. and its plant expressing vector construction. Chin. Agr. Sci. Bull. 30:148-153. (in Chinese), doi: 10.11924/j.issn.1000-6850.2014-0400.
Yang, A. Z., Z.Y. Zhang, A.J. Cao, H.L. Meng, and Y.N. Wang. 2009. Studies of changes in sugar accumulation and lignin deposition during peach fruit endocarp development. Acta Hort. Sin. 36:1113-1119. (in Chinese), doi: 10.16420/j.issn.0513-353x.2009.08.004.

Yang, Z.H. 2000a. Maximum likelihood estimation on large phylogenies and analysis of adaptive evolution in human influenza virus A. J. Mol. Evol. 51:423-432, doi: 10.1007/s002390010105.

Yang, Z.H. 2000b. Complexity of the simplest phylogenetic estimation problem. Proc. Biol. Sci. 267:109-116, doi: 10.1098/rspb.2000.0974.

Yang, Z.H. and R. Nielsen. 1998. Synonymous and nonsynonymous rate variation in nuclear genes of mammals. J. Mol. Evol. 46:409-418, doi: 10.1093/oxfordjournals.molbev.a040153.

Yao, L.M., X.Q. Hu, F. Zhou, Y.Q. Zheng, G.D. Wang, and X.M. Liu. 2019. Antisense CCoAOMT gene regulates lignin biosynthesis in Betula platyphylla. Bull. Bot. Res. 39:123 -130. (in Chinese), doi: 10.7525/j.issn.1673-5102.2019.01.015.

Yuan, Z.Y., H.L. Zhou, T. Tian, X.X. Zhang, and Y.X. Pan. 2014. Effects and mechanism of aloe vera extracts on control of botrytis in postharvest apples. Trans. Chin. Soc. Agric. Eng. 30:255-263. (in Chinese), doi: 10.3969/j.issn.1002-6819.2014.04.031.

Zaffolon, V., A. Tadiello, A. Rasori, C. Forcato, N. Vitulo, S. Cagnin, A. Ramina, C. Bonghi, and L. Trainotti. 2017. Genome wide transcriptional changes during peach fruit development. 1 Dec. 2017. <https://www.ncbi.nlm.nih.gov/geo/query/acc.cgi? acc $=$ GSE71561>.

Zhang, L.M., H. Kamitakahara, H. Murayama, T. Ohsako, and A. Itai. 2020. Analysis of fruit lignin content, composition, and linkage types in pear cultivars and related species. J. Agr. Food Chem. 68: 2493-2505, doi: 10.1021/acs.jafc.9b07396.

Zhao, H.Y., Q.X. Shen, S.Y. Lu, T. Wang, and Y.R. Song. 2004. Characterization of three rice CCOAOMT genes. Chin. Sci. Bull. 49:1390-1394. (in Chinese).

Zhong, R., W.H. Morrison, D.S. Himmelsbach, F.L. Poole, and Z.H. Ye. 2000. Essential role of caffeoyl coenzyme A O-Methyltransferase in lignin biosynthesis in woody poplar plants. Plant Physiol. 124: 563-577, doi: 10.1104/pp.124.2.563.

Zhong, R., W.H. Morrison, J. Negrel, and Z.H. Ye. 1998. Dual methylation pathways in lignin biosynthesis. Plant Cell 10:2033-2046, doi: $10.2307 / 3870782$. 